\title{
52 Table
}

\section{Risk of bias of the included RCTs}

\begin{tabular}{|c|c|c|c|c|c|c|c|c|}
\hline \multirow[b]{2}{*}{ Study } & \multirow{2}{*}{$\begin{array}{c}\text { Quality } \\
\text { Judgment }\end{array}$} & \multicolumn{7}{|c|}{ Risk bias } \\
\hline & & 1 & 2 & 3 & 4 & 5 & 6 & 7 \\
\hline $\begin{array}{l}\text { Abou-Assi } \\
\text { et al., } 2002\end{array}$ & Minor considered & $?^{8}$ & $?$ & -9 & - & $+^{10}$ & + & + \\
\hline $\begin{array}{c}\text { Casas et al., } \\
2007\end{array}$ & Minor considered & + & + & - & - & + & + & $?$ \\
\hline $\begin{array}{c}\text { Doley et al., } \\
2009\end{array}$ & Major considered & - & - & - & - & + & + & + \\
\hline $\begin{array}{c}\text { Du et } \\
\text { al.,2015 }\end{array}$ & Major considered & $?$ & $?$ & - & - & + & + & $?$ \\
\hline $\begin{array}{c}\text { Eckerwall et } \\
\text { al., } 2006\end{array}$ & Minor considered & + & + & - & - & + & + & $?$ \\
\hline $\begin{array}{l}\text { Entock et al., } \\
2005\end{array}$ & Minor considered & + & + & - & - & + & + & $?$ \\
\hline $\begin{array}{c}\text { Gupta et al., } \\
2003\end{array}$ & Minor considered & + & + & - & - & + & + & $?$ \\
\hline $\begin{array}{c}\text { He et al., } \\
2004\end{array}$ & Major considered & $?$ & $?$ & - & - & + & + & $?$ \\
\hline $\begin{array}{c}\text { Kalfarentzos } \\
\text { et al., } 1997\end{array}$ & Minor considered & + & + & - & - & + & + & $?$ \\
\hline $\begin{array}{c}\text { Kumar et al., } \\
2006\end{array}$ & Minor considered & + & + & - & - & + & + & $?$ \\
\hline $\begin{array}{c}\text { McClave et } \\
\text { al., } 1997\end{array}$ & Major considered & $?$ & $?$ & - & - & + & + & $?$ \\
\hline $\begin{array}{l}\text { Louie et al., } \\
\qquad 2005\end{array}$ & Minor considered & + & + & - & - & + & + & + \\
\hline $\begin{array}{c}\text { MIMOSA } \\
\text { trial }\end{array}$ & Minor considered & + & + & - & - & + & + & + \\
\hline $\begin{array}{l}\text { Olah et al., } \\
2002\end{array}$ & Major considered & - & - & - & - & + & + & $?$ \\
\hline $\begin{array}{l}\text { Petrov et al., } \\
2006\end{array}$ & Minor considered & + & + & - & - & + & + & $?$ \\
\hline $\begin{array}{l}\text { Powell et al., } \\
2000\end{array}$ & Minor considered & $?$ & $?$ & - & - & + & + & + \\
\hline $\begin{array}{c}\text { Sax et al., } \\
1987\end{array}$ & Major considered & $?$ & $?$ & - & - & + & + & $?$ \\
\hline $\begin{array}{l}\text { Singh et al., } \\
2012\end{array}$ & Minor considered & + & + & - & + & + & + & + \\
\hline $\begin{array}{c}\text { Stimac et al., } \\
2016\end{array}$ & Minor considered & + & + & - & - & + & + & + \\
\hline $\begin{array}{c}\text { Wang et al., } \\
2013\end{array}$ & Major considered & $?$ & $?$ & - & - & + & + & $?$ \\
\hline $\begin{array}{c}\text { Wu et al., } \\
2010\end{array}$ & Major considered & $?$ & $?$ & - & - & + & + & $?$ \\
\hline $\begin{array}{l}\text { Zhang et al., } \\
2011\end{array}$ & Major considered & $?$ & $?$ & - & - & + & + & $?$ \\
\hline
\end{tabular}

1 sequence generation; 2 allocation concealment; 3 blinding of participants and personnel; 4 blinding of outcome assessment; 5 incomplete outcome data; 6 selective reporting; 7 other bias. ${ }^{8}$ Yellow with ?, risk unclear; ${ }^{9}$ Red with -, high risk; ${ }^{10}$ Green with + , low risk. 